\title{
Pengaruh Penerapan Discharge Planning ROM Dan Ambulasi Terhadap Kesiapan Keluarga Dalam Merawat Pasien Pasca Stroke Di RSUD Sultan Syarif Mohammad Alkadrie Kota Pontianak
}

\author{
Mita Widya Ningrum* Arina Nurfianti ** Saiman** \\ *Mahasiswa S1 Keperawatan, ** Dosen Keperawatan PSIK \\ Email : mitawningrum@gmail.com
}

\begin{abstract}
ABSTRAK
Latar Belakang : Stroke merupakan penyakit pada otak berupa gangguan fungsi syaraf lokal dan global yang muncul mendadak progresif dan cepat. Gangguan fungsi syaraf pada stroke disebabkan oleh gangguan peredaran darah otak non trauatik. Discharge planning ROM dan ambulasi bermanfaat dalam mencegah kakunya ekstremitas atas dan bawah yang mengalami stroke serta melihat kesiapan keluarga saat merawat anggota keluarga.

Tujuan : Mengidentifikasi pengaruh penerapan discharge planning ROM dan ambulasi terhadap kesiapan keluarga dalam merawat pasien pasca stroke di RSUD Sultan Syarif Mohammad Alkadrie Kota Pontianak.

Metode : Penelitian kuantitatif menggunakan pendekatan quasy experimental dalam kategori (pretest - posttest control group design) pada 36 responden yaitu 18 responden kelompok intervensi dan 18 responden kelompok kontrol. Data penelitian ini dianalisis menggunakan uji Wilcoxon

Hasil : Hasil kesiapan keluarga pada kelompok intervensi didapatkan $p$ value = 0,0003 sedangkan pada kelompok kontrol $p$ value $=0,014$ dengan standar deviasi sebelum dan sesudah pada kelompok intervensi $(1,018-2,445)$ pada kelompok kontrol (1,676-1,680). Hasil dapat diasumsikan bahwa discharge planning dengan metode latihan ROM dan ambulasi lebih efektif diberikan kepada kelompok intervensi dibandingkan dengan kelompok kontrol.
\end{abstract}

Kesimpulan : Ada pengaruh penerapan discharge planning terhadap kesiapan keluarga dalam merawat pasien pasca stroke di RSUD Sultan Syarif Mohammad Alkadrie Kota Pontianak dan ada perbedaan yang bermakna antara kelompok intervensi dan kelompok kontrol.

Kata Kunci : Stroke, discharge planning, kesiapan keluarga 


\title{
Effect Of Determination Of Discharge Planning ROM And Ambulation To The Preparation Of Family Subject Post-Stroke Patients In RSUD Sultan Syarif Mohammad Alkadrie Pontianak City
}

\begin{abstract}
Background: Stroke is a disease of the brain in the form of disorders of local and global nervous function that appears suddenly progressive and rapid. Nerve function impairment in stroke is caused by non traumatic brain circulation disorder. Discharge planning with ROM and ambulation are benefit in preventing of the upper and lower extremities of the stroke and seeing family preparedness when caring for family members.

Aims: To identify the effect of ROM discharge planning implementation and ambulation on family preparedness in caring for post stroke patient at RSUD Sultan Syarif Mohammad Alkadrie Pontianak City.

Methods: Quantitative research using experimental quasy approach in category (pretest - posttest control group design) on 36 respondents that is 18 responden intervention group and 18 respondent of control group. This research data was analyzed using Wilcoxon

Results: The result of family preparedness in intervention group got $p$ value $=$ 0.0003 while in control group $p$ value $=0,014$ with standard deviation before and after in the intervention group (1.018-2.445) in the control group (1.676-1.680). The results can be assumed that discharge planning by ROM practice method and ambulation is more effectively given to the intervention group than the control group.

Conclusions: There is an effect of applying discharge planning to family preparedness in caring post-stroke patient at Sultan Syarif Mohammad Alkadrie Hospital of Pontianak Municipality and there is a significant difference between intervention group and control group.
\end{abstract}

Keywords: Stroke, discharge planning, family preparedness 


\section{PENDAHULUAN}

Stroke didefinisikan sebagai serangan tiba-tiba defisit neurologis fokal, seperti gangguan kekuatan, berbicara, penglihatan dan pergerakan yang konsisten dengan distribusi pembuluh darah yang berlangsung lebih dari 24 jam dengan atau tanpa gambaran positif serta kurang dari 24 jam dengan gambaran positif (Morgan and Joseph $\mathrm{H}$. Ricker, 2008).

Prevalensi stroke secara global, 15 juta orang terserang stroke setiap tahunnya, satu pertiga meninggal dan sisanya mengalami kecacatan permanen (Stroke forum, 2015). Stroke merupakan penyebab utama kecacatan yang dapat dicegah (American Heart Association, 2014).

Prevalensi stroke di Indonesia berdasarkan diagnosis tenaga kesehatan sebesar 7 per mil dan yang terdiagnosis tenaga kesehatan atau gejala sebesar 12,1 per mil. Prevalensi Stroke berdasarkan diagnosis nakes tertinggi di Sulawesi Utara (10,8 \%o), diikuti DI Yogyakarta (10,3 \%o), Bangka Belitung dan DKI Jakarta masing masing 9,7 per mil. Prevalensi Stroke berdasarkan terdiagnosis nakes dan gejala tertinggi terdapat di Sulawesi Selatan (17,9\%o), DI Yogyakarta (16,9\%o), Sulawesi Tengah
(16,6\%), diikuti Jawa Timur sebesar 16 per mil (Riskesdas, 2013).

Data Departemen Kesehatan yang dikeluarkan pada tahun 2007, ditemukan 8,3 per 1000 orang penduduk menderita stroke. Sedangkan pada tahun 2013, angka kejadian stroke meningkat tajam menjadi 12,1 per 1000 orang. Berdasarkan data yang dikeluarkan, didapatkan bahwa Kota Pontianak adalah kota dengan jumlah penderita stroke yang tinggi. Data menunjukkan bahwa 14,9 per 1000 orang penduduk Kota Pontianak menderita stroke. Angka tersebut jelas lebih tinggi dari angka rata-rata nasional yaitu 12,1 per 1000 orang menderita stroke.

Hasil studi pendahuluan yang dilakukan di ruang perawatan bedah RSUD Sultan Syarif Mohammad Alkadrie Kota Pontianak diperoleh data pada bulan Agustus 2017 melalui wawancara. Dari hasil wawancara yang dilakukan peneliti didapatkan bahwa discharge planning dirumah sakit jarang dilakukan oleh perawat. Lama pasien stroke yang dirawat juga berbagai macam mulai dari 4 hari, 7 hari sampai 1 bulan. Tingkat keberhasilan terapi yang dilakukan juga berlangsung lama. Untuk melihat perkembangan pasien, perawat 
dan terapi menyarankan untuk kontrol ulang kembali ke rumah sakit.

Adanya fenomena seperti ini maka peneliti tertarik untuk meneliti lebih lanjut tentang "Pengaruh Penerapan Discharge Planning Terhadap Kesiapan Keluarga Dalam Merawat Pasien Pasca Stroke di RSUD Sultan Syarif Mohammad Alkadrie Kota Pontianak”.

\section{METODE PENELITIAN}

Penelitian ini merupakan penelitian kuantitatif menggunakan desain penelitian Quasy Experimental dengan

Analisa univariat bertujuan untuk mendeskripsikan masing-masing variabel yang diteliti. Bentuk univariat tergantung jenis datanya (Nursalam, 2011). Analisa bivariat adalah analisis rancangan pretest - posttest control grup design. Dalam penelitian ini menggunakan purposive sampling berdasarkan maksud dan tujuan yang masuk dalam kriteria inklusi dan eklusi peneliti. Adapun kriteria inklusi pada penelitian ini diantaranya primary caregiver, usia dewasa dan tidak mengalami kelainan kognitif dan pendidikan keluarga minimal sekolah dasar. Sedangkan kriteria eksklusi pada penelitian ini diantaranya Keluarga dengan latar belakang bidang kesehatan dan keluarga dengan GCS (Glassgow Coma Scale) kurang dari 8.

untuk menguji hubungan yang signifikan antara dua variabel. Penelitian ini menggunakan uji Wilcoxon karena distribusi data tidak normal.

\section{HASIL PENELITIAN}

Karakteristik Responden Tabel 4.1 Karakteristik Responden ( $n=36)$

\begin{tabular}{ccccccc}
\hline \multirow{2}{*}{ Variabel } & \multicolumn{2}{c}{ Intervensi } & \multicolumn{2}{c}{ Kontrol } & \multicolumn{2}{c}{ Total } \\
\cline { 2 - 7 } & $\mathrm{N}$ & $\%$ & $\mathrm{n}$ & $\%$ & $\mathrm{n}$ & $\%$ \\
\hline Jenis Kelamin & & & & & & \\
$\quad$ Laki-laki & 10 & 55,6 & 7 & 38,9 & 17 & 47,25 \\
$\quad$ Perempuan & 8 & 44,4 & 11 & 61,1 & 19 & 52,75 \\
\hline Usia & & & & & & \\
17-25 Tahun & 3 & 16,7 & 4 & 22,2 & 7 & 19,45 \\
26-35 Tahun & 5 & 27,8 & 2 & 11,1 & 7 & 19,45 \\
36-45 Tahun & 4 & 22,2 & 6 & 33,3 & 10 & 27,75
\end{tabular}




\begin{tabular}{ccccccc} 
46-55 Tahun & 3 & 16,7 & 6 & 33,3 & 9 & 25 \\
56-65 Tahun & 2 & 11,1 & - & - & 2 & 5.55 \\
65 tahun keatas & 1 & 5,6 & - & - & 1 & 2,8 \\
\hline Tingkat Pendidikan & & & & & & \\
SD & 2 & 11,1 & 3 & 16,7 & 5 & 13,9 \\
SMP & 6 & 33,3 & 5 & 27,8 & 11 & 30,55 \\
SMA & 9 & 50,0 & 6 & 33,3 & 15 & 41,65 \\
DIII & 1 & 5,6 & 1 & 5,6 & 2 & 5,6 \\
DIV & - & - & 1 & 5,6 & 1 & 2,8 \\
S1 & - & - & 2 & 11,1 & 2 & 5,55 \\
\hline
\end{tabular}

Sumber : data primer yang telah diolah. 2018

Berdasarkan hasil analisis pada kelompok kontrol adalah pada rentang tabel 4.1 dapat disimpulkan bahwa 36-45 tahun. Tingkat pendidikan jumlah responden kelompok intervensi dan kelompok kontrol terbanyak adalah berjenis kelamin perempuan. Jumlah usia responden kelompok intervensi dan responden kelompok intervensi yang paling banyak adalah taraf SMA. Tingkat pendidikan responden kelompok kontrol paling banyak juga taraf SMA.

\section{Karakteristik Responde Berdasarkan Kesiapan Keluarga Sebelum dan Sesudah Dilakukan Intervensi}

Tabel 4.2 Kesiapan Keluarga Sebelum dan Sesudah Dilakukan Intervensi (n=36)

\begin{tabular}{lcccc}
\hline \multicolumn{1}{c}{ Kelompok } & $\mathrm{n}$ & $\begin{array}{c}\text { Sebelum } \\
\text { Median (min-max) }\end{array}$ & $\begin{array}{c}\text { Sesudah } \\
\text { Median (min-max) }\end{array}$ & $\begin{array}{c}\text { Std. Dev } \\
\text { (Pre - Post) }\end{array}$ \\
\hline Intervensi & 18 & $16(13-16)$ & $19,50(14-22)$ & $(1,018-2,445)$ \\
Kontrol & 18 & $15,50(12-19)$ & $16(13-19)$ & $(1,676-1,680)$ \\
\hline
\end{tabular}

Sumber : data primer yang telah diolah, 2018

Berdasarkan hasil analisis pada tabel 4.2 dapat dilihat nilai kesiapan keluarga sebelum intervensi pada kelompok intervensi didapatkan bahwa nilai median kesiapan keluarga adalah 16 dengan nilai terendah 13 dan nilai tertinggi 16, sedangkan pada kelompok kontrol nilai median kesiapan keluarga 15,50 dengan nilai terendah 12 dan nilai tertinggi 19.
Nilai kesiapan keluarga sesudah intervensi pada kelompok intervensi didapatkan bahwa nilai median kesiapan keluarga adalah 19,50 dengan nilai terendah 14 dan nilai tertinggi 22, sedangkan pada kelompok kontrol nilai median kesiapan keluarga adalah 16 dengan nilai terendah 13 dan nilai tertinggi

19. 
Perbedaan Kesiapan Keluarga pada Kelompok Intervensi dan

Kelompok Kontrol

\begin{tabular}{lccccc}
\hline \multicolumn{1}{c}{ Kelompok } & $\mathrm{n}$ & $\begin{array}{c}\text { Sebelum } \\
\text { Median (min-max) }\end{array}$ & $\begin{array}{c}\text { Sesudah } \\
\text { Median (min-max) }\end{array}$ & $\begin{array}{c}\text { Std. Dev } \\
(\text { Pre }- \text { Post })\end{array}$ & $p$ \\
\hline Intervensi & 18 & $16(13-16)$ & $19,50(14-22)$ & $(1,018-2,445)$ & 0,0003 \\
Kontrol & 18 & $15,50(12-19)$ & $16(13-19)$ & $(1,676-1,680)$ & 0,014 \\
\hline \multicolumn{2}{l}{ Sumber : Hasil uji Wilcoxon. } & & &
\end{tabular}

Berdasarkan pada uji statistik pada tabel 4.3, kesiapan keluarga pada kelompok intervensi didapatkan $p$ value $=0,0003$ sehingga dapat disimpulkan bahwa terdapat pengaruh penerapan discharge planning terhadap kesiapan keluarga pada kelompok intervensi sebelum dan sesudah diberikan $R O M$ dan ambulasi. Pada kelompok kontrol didapatkan $p$ value $=0,014$, sehingga dapat disimpulkan pada kelompok kontrol kesiapan keluarga sebelum dan sesudah tidak mengalami perubahan.

\section{PEMBAHASAN}

Hasil penelitian menunjukkan bahwa terdapat pengaruh kesiapan keluarga pada kelompok intervensi setelah dilakukan intervensi $R O M$ dan Ambulasi. ROM dan Ambulasi merupakan salah satu latihan dasar yang dilakukan untuk melatih kekuatan otot agar tidak terjadi kekauan diekstremitas atas dan bawah pasien stroke di RSUD Sultan Syarif Mohammad Alkadrie Kota Pontianak. Peneliti memiliki pendapat yang sama bahwa intervensi $R O M$ dan Ambulasi yang dilakukan dapat berpengaruh terhadap keluarga pasien khususnya dalam latihan gerak dasar. Keluarga pasien mampu mengikuti arahan dari perawat dan sesuai dengan discharge planning yang diajarkan dengan tujuan untuk mencegah kekakuan otot pada ekstremitas atas dan bawah pasien stroke dalam jangka waktu yang lama.

Penelitian ini sejalan dengan penelitian Marlina (2017), bahwa pelaksanaan latihan ROM pada pasien stroke secara intens, terarah dan teratur, maka dapat mempengaruhi kemampuan motorik pasien untuk meningkatkan kemandirian. Setelah latihan ini dilakukan maka pasien dapat melakukan aktivitas sehari-hari sehingga pasien pulang tidak lagi ketergantungan pada perawat dan keluarga ataupun orang lain. Hasil uji statistik menunjukkan bahwa selisih peningkatan kekuatan otot kelompok intervensi sebelum dan sesudah latihan ROM dapat disimpulkan bahwa ada pengaruh yang bermakna latihan ROM terhadap peningkatan kekuatan otot pada pasien stroke iskemik di ruang Saraf Rumah Sakit Umum Daerah dr. Zainoel Abidin Banda Aceh. 
Hal ini terjadi karena intervensi yang diberikan sesuai dengan landasan teori dan intens latihan yang teratur dan tepat.

Membahas tentang kesiapan keluarga penelitian ini sejalan dengan penelitian yang dilakukan oleh Pierce, Steiner, Govoni, Thompson dan Firdemann tahun (2007) dalam Daulay (2014), menunjukkan bahwa caregiver akan berhasil dalam menjalankan tugasnya dalam merawat pasien stroke dalam rentang satu tahun ke atas. Mulai kurun waktu sampai dengan enam bulan pertama setelah serangan stroke, caregiver masih berusaha untuk menerima kondisi pasien stroke, belajar untuk menyesuaikan diri dengan keadaan, dan belajar cara merawat pasien stroke. Sehingga dalam penelitian ini, beberapa caregiver yang merawat pasien stroke lebih dari satu tahun mengeluh mengalami beban psikologis dan stres dalam merawat anggota keluarga yang menderita stroke.

Membahas tentang discharge planning penelitian ini sejalan dengan penelitian Williams (2006) dalam Siahaan (2009) yang mendapati adanya hubungan antara pemberian informasi dengan dilakukannya kunjungan ulang yang tidak rutin ke fasilitas kesehatan.
Dalam tersebut Williams mendapati bahwa mayoritas pasien yang menerima informasi tentang nyeri dan manajemen luka, aktivitas, nutrisi dan komplikasi pada umumnya merasakan bahwa tidak mengalami perasaan khawatir yang membuat mereka akan mengadakan kunjungnan tidak rutin ke fasilitas kesehatan setelah dipulangkan, dalam artian bahwa mereka telah siap menghadapi pemulangan. Sedangkan pasien yang tidak mendapatkan informasi tentang nyeri dan manajemen luka mengalami kekhawatiran yang memaksa mereka untuk melakukan kunjungan tidak rutin kepada suatu fasilitas kesehatan setelah dipulangkan.

\section{SIMPULAN}

Berdasarkan hasil penelitian yang telah dilakukan dapat disimpulkan bahwa ada pengaruh penerapan discharge planning rom dan ambulasi terhadap kesiapan keluarga dalam merawat pasien pasca stroke di RSUD Sultan Syarif Mohammad Alkadrie Kota Pontianak. 


\section{DAFTAR PUSTAKA}

American Heart Association (AHA).

Heart Disease and Stroke Statistic.

Circulation 2013; (127): e6-e245.

Daulay, Nanda Masrani. Setiawan. S.

Nunung Febriany. (2014).

Pengalaman Keluarga Sebagai

Caregiver dalam Merawat Pasien

Stroke di Rumah. Naskah

Publikasi. Vol. 2 No. 3. Desember 2014.

Joel E. Morgan \& Joseph H. Ricker. Textbook of Clinical Neuropsychology : A New Benchmark In The Study of BrainBehavior Relationships. New York : Pshychology Press. 1048pp. 2008

Kementrian Kesehatan RI. Riset kesehatan dasar (Riskesdas) 2013. Jakarta: Badan Penelitian dan Pengembangan Kesehatan Kementrian Kesehatan RI. 2013 http://www.depkes.go.id/resources /download/general/Hasil\%20Riske sdas\%202013.pdf tanggal akses 3 Februari 2017

Marlina. (2017). Pengaruh Latihan ROM Terhadap Peningkatan Kekuatan Otot Pada Pasien Stroke Iskemik di RSUDZA Banda Aceh. Idea Nursing Journal. ISSN : 20872879 Vol. III No.1

Nursalam. (2011). Konsep dan Penerapan Metodologi Penelitian Ilmu Keperawatan Pedoman Skripsi, Tesis, dan Instrumen Penelitian Keprawatan. Jakarta: Salemba Medika

Siahaan, Marthalena. (2009). Pengaruh Discharge Planning yang Dilakukan oleh Perawat terhadap Kesiapan Pasien Pasca Bedah Akut Abdomen Mneghadapi Pemulangan di RSUP H. Adam Amlik Medan. Universitas Sumatera Utara. Skripsi 